\title{
Differential expression, molecular cloning, and characterization of porcine beta defensin 114
}

\author{
Guoqi Su ${ }^{1,2}$, Kunhong Xie ${ }^{1,2}$, Daiwen Chen ${ }^{1,2}$, Bing Yu ${ }^{1,2}$, Zhiqing Huang ${ }^{1,2}$, Yuheng Luo ${ }^{1,2}$, Xiangbing Mao ${ }^{1,2}$,
} Ping Zheng ${ }^{1,2}$, Jie $\mathrm{Yu}^{1,2}$, Junqiu Luo ${ }^{1,2}$ and Jun $\mathrm{He}^{1,2^{*}}$ (D)

\begin{abstract}
Background: $\beta$-defensins have attracted considerable research interest because of their roles in protecting hosts from various pathogens. This study was conducted to investigate the expression profiles of the porcine $\beta$-defensin 114 (PBD114) in different breeds and in response to infections. Moreover, the function of PBD114 protein was partially investigated.

Methods: Six Tibetan pigs (TP) and six DLY (DurocXLandracexYorkshire) pigs were slaughtered to explore the expression profiles of PBD114 in different breeds and tissues. For infection models, sixteen DLY pigs were divided into two groups and challenged either with sterile saline or E. coli K88. The recombinant protein PBD114 (rPBD114) was obtained by using a heterologous expression system in E. coli.

Results: PBD114 gene was highly expressed in tissues such as the intestine, liver, spleen, and thymus. Interestingly, the expression level of PBD114 gene was higher in the TP pigs than in the DLY pigs $(P<0.05)$, and was significantly elevated upon E. coli K88 challenge $(P<0.05)$. The nucleotide sequences of PBD114 from Tibetan and DLY pigs was identical, and both showed a 210-bp open reading frame encoding a 69-amino acid mature peptide. To explaore the function of PBD114 protein, PBD114 gene was successfully expressed in E. coli Origami B (DE3) and the molecular weight of the rPBD114 was estimated by SDS-PAGE to be $25 \mathrm{kDa}$. The rPBD114 was purified and mass spectrometry verified the protein as PBD114. Importantly, rPBD114 showed antimicrobial activities against E. coli DH5a and E. coli K88, and the minimal inhibitory concentrations (MICs) were 64 and $128 \mu \mathrm{g} / \mathrm{mL}$, respectively. Hemolytic and cytotoxicity assays showed that rPBD114 did not affect cell viability under physiological concentrations.

Conclusions: PBD114 is an infection response gene that is differentially-expressed between different porcine breeds and tissues. The antimicrobial activity of PBD114 protein, against pathogens such as the $E$. coli K88, suggested that it may serve as a candidate for the substitution of conventionally used antibiotics.
\end{abstract}

Keywords: Antimicrobial activity, DLY, E. coli, Porcine beta defensin 114, Tibetan

\section{Introduction}

The availability of antibiotics for treating bacterial infections has significantly improved the health of animals and humans. In addition, sub-therapeutic levels of antibiotics have been added to pig feed as growth promoters in many countries [1]. However, liberal antibiotic use

\footnotetext{
* Correspondence: hejun8067@163.com

${ }^{1}$ Animal Nutrition Institute, Sichuan Agricultural University, Chengdu 611130, People's Republic of China

${ }^{2}$ Key Laboratory for Animal Disease-Resistance Nutrition of China Ministry of Education, Sichuan Agricultural University, Chengdu 625014, People's
} Republic of China combined with the ability of microorganisms to develop antibiotic resistance has led to multi-drug resistant, which has fuelled a potential global public health crisis [2]. To reduce the emergence of antimicrobial resistance, approaches to reduce the utilization of antibiotics in animal production are needed.

Innate immunity is the first line of host defense against invading pathogens such as bacteria, virus, and fungus. Previous studies have indicated that one of the primary innate immune responses are the secretion of antimicrobial peptides (AMPs) [3, 4]. To date, thousands 
of antimicrobial peptides (AMPs) have already been identified in vertebrates, invertebrates, plants and fungi (http://aps.unmc.edu/AP/main.php). AMPs are classified based on structural and sequence homology, with host defence peptides (HDPs) comprising one of the major subclasses of the family of AMPs [5]. HDPs are a family of low molecular weight peptides secreted by organisms, and can protect hosts from a broad range of pathogens including bacteria, virus and fungus [3-5]. Upon microbial invasion, mature active HDPs are released quickly by proteolytic processing from precursor peptides either in cytoplasmic granules of most mammalian neutrophils and macrophages or in epithelial cells of the respiratory, gastroenteric, and urogenital tracts [6, 7]. HDPs disrupt the bacterial membrane by forming non-specifc electrostatic interactions with the membrane lipid components [8]. So bacteria are less able to develop resistance to HDPs than to traditional antibiotics. Therefore, the administration of HDPs is a potentially novel therapeutic strategy for inflammatory and infectious diseases of the gastrointestinal tract $[7,9]$, and may present a promising alternative to the traditional antibiotic feed additives used in the livestock industry.

The first identified porcine beta defensin was porcine beta defensin 1 (PBD1), which can be detected throughout the respiratory and digestive tracts [6]. Further studies found that PBD1 displayed strong antimicrobial activity against Bordetella pertussis, Staphylococcus aureus and multi-resistant $E$. coli [10-12]. In addition, previously reported that porcine beta defensin (PBD2) was expressed in the intestine, and mature PBD2 synthetic peptide exhibited high antimicrobial activity against a broad range of pathogenic bacteria, but only limited hemolytic activity against porcine red blood cells $[1,12]$. A recent study reported that there were at least 29 different $\beta$-defensins expressed in porcine tissues. The average nucleotide sequence identity from the 27 pairs of orthologous $\beta$-defensins between humans and pigs was $84.38 \%$, and this probably indicated that $\beta$-defensins have multiple biological functions [13]. Although the porcine beta defensins may function as an important regulator of host defense against exogenous pathogens, the expression profile and biological functions of PBD114 are still unclear. The present study was conducted to explore the expression profiles of the PBD114 in different breeds and in response to infections. Moreover, the function of PBD114 protein has also been investigated.

\section{Materials and methods}

\section{Strains and vectors}

E. coli $\mathrm{DH} 5 \alpha$ and E. coli Origami B (DE3) strains were purchased from TIANGEN (Beijing, China). E. coli K88 was kindly provided by Professor Lianqiang Che, Institute of Animal Nutrition, Sichuan Agricultural University. Salmonella typhimurium (S. typhimurium) ATCC14028, Staphylococcus aureus (S. aureus) CICC10384, Streptococcus, Pichia pastoris X33 and Bacillus subtilis (B. subtilis) were kindly provided by Professor Qigui Yan, College of Animal Science and Technology, Sichuan Agricultural University. The plasmids pMD19-T Simple and pET32a (+) were purchased from Takara (Dalian, China) and Merck KGaA (Darmstadt, Germany) respectively.

\section{Animals}

Six 60 days old TP $(6.63 \pm 0.85 \mathrm{~kg})$ and six 60 days old DLY $(21.72 \pm 0.36 \mathrm{~kg})$ pigs were purchased from the animal husbandry science research institute, Ganzi Tibetan Autonomous Prefecture in Sichuan Province. All pigs were immediately euthanized to collect liver, spleen, kidney, lung, thymus, duodenum, jejunum, ileum, cecum and colon, then collected tissues were immediately snapfrozen in liquid nitrogen for quantitative real-time PCR.

Sixteen 7 days old DLY pigs $(3.14 \pm 0.07 \mathrm{~kg})$ were purchased from the Sichuan Giastar Group. All pigs were randomly divided into two groups: CON and K88. Pigs of K88 group and CON group were given a gavage of 80 $\mathrm{mL} 1 \times 10^{9} \mathrm{CFU} / \mathrm{mL}$ E. coli $\mathrm{K} 88$ and the same volume normal saline respectively. Diarrhoea scores were recorded every $4 \mathrm{~h}$ for a total $24 \mathrm{~h}$ after challenge. Artificial milk (Table 1 ) was fed every $3 \mathrm{~h}$ during the study period. After the experiment, all pigs were euthanized to collect duodenum, jejunum, ileum, cecum and colon, and then immediately snap-frozen in liquid nitrogen for quantitative real-time PCR.

\section{Cell culture}

Intestinal porcine epithelial cells (IPEC-J2) were cultured in $75 \mathrm{~cm}^{2}$ cell culture flask in DMEM-F12 with $10 \%$ FBS, $100 \mathrm{U} / \mathrm{mL}$ penicillin, and $100 \mu \mathrm{g} / \mathrm{mL}$ streptomycin. $1 \times 10^{5}$ cells/well were seeded in 12 -well plates and grown to $\sim 80 \%$ confluence at $37^{\circ} \mathrm{C}$ in a $\mathrm{CO}_{2}$ incubator $(5 \% v / v)$, then cultured for $12 \mathrm{~h}$ in culture medium without FBS and penicillin-streptomycin. Cells were challenged with $1 \times 10^{5 / 6 / 7} \mathrm{CFU} /$ well E. coli $\mathrm{K} 88$ for $1.5 \mathrm{~h}$, control cells were not challenged. Total cellular RNA was collected using RNAiso Plus (Takara, Dalian, China).

\section{Total RNA isolation and PCR}

Total RNA was isolated from pigs using RNAiso Plus (Takara, Dalian, China) according to the manufacturer's instructions. The quantity and quality of the isolated RNA were determined by absorbance at 260 and $280 \mathrm{~nm}$ [14]. And then cDNA was synthesized using a Reverse Transcriptase kit (Takara, Dalian, China). Subsequently, PBD114 cDNA was amplified by PCR using the following specific primers which were designed online: forward 
Table 1 Composition and nutrient content of artificial milk (87.5\% DM basis)

\begin{tabular}{|c|c|}
\hline Items & Control \\
\hline \multicolumn{2}{|l|}{ Ingredients, \% } \\
\hline Whole milk powder, 24\% CP & 58.00 \\
\hline Whey protein concentrate, $34 \%$ CP & 25.00 \\
\hline Casein & 2.00 \\
\hline Coconut oil & 12.40 \\
\hline $\mathrm{CaH}_{2} \mathrm{PO}_{4}, 22 \% \mathrm{P}$ & 0.10 \\
\hline Choline chloride, $50 \%$ & 0.10 \\
\hline Vitamin mixture ${ }^{a}$ & 0.10 \\
\hline Mineral mixture $e^{b}$ & 0.50 \\
\hline L-Alanine, 95\% & 0.85 \\
\hline L-Leu, 95\% & - \\
\hline L-Arg, 98.5\% & 0.06 \\
\hline DL-Met, $98.5 \%$ & 0.06 \\
\hline L-Lys.HCl, 78.5\% & 0.75 \\
\hline L-Thr, 98\% & 0.03 \\
\hline L-Trp, 98\% & 0.05 \\
\hline \multicolumn{2}{|l|}{ Nutrient content ${ }^{c}$} \\
\hline Crude protein, $\%$ & 26.13 \\
\hline Digestible energy, MJ/kg & 19.21 \\
\hline Calcium, \% & 1.02 \\
\hline Total phosphorus, \% & 0.81 \\
\hline Available phosphorus, $\%$ & 0.67 \\
\hline Total isoleucine, \% & 1.24 \\
\hline Total leucine, \% & 2.40 \\
\hline Total valine, $\%$ & 1.36 \\
\hline Total lysine, $\%$ & 2.19 \\
\hline Total methionine, \% & 0.79 \\
\hline Total arginine, $\%$ & 0.77 \\
\hline
\end{tabular}

$C P$ crude protein

${ }^{a}$ Vitamin premix provided per kg powder diet: vitamin $A, 0.94 \mathrm{mg}$; vitamin $\mathrm{D}_{3}$, $0.01 \mathrm{mg}$; vitamin $\mathrm{E}, 20 \mathrm{mg}$; vitamin $\mathrm{K}_{3}, 1 \mathrm{mg}$; vitamin $\mathrm{B}_{12}, 0.04 \mathrm{mg}$; riboflavin, 5 $\mathrm{mg}$; niacin, $20 \mathrm{mg}$; pantothenic acid, $15 \mathrm{mg}$; folic acid, $1.5 \mathrm{mg}$; thiamin, $1.5 \mathrm{mg}$; pyridoxine, $2 \mathrm{mg}$; biotin, $0.1 \mathrm{mg}$

${ }^{\mathrm{b}}$ Mineral premix provided per kg powder diet: Zn, 90 mg; Mn, 4.0 mg; Fe, 90 $\mathrm{mg} ; \mathrm{Cu}, 6.0 \mathrm{mg}$;, $0.2 \mathrm{mg}$; Se, $0.3 \mathrm{mg}$

'All nutrient contents, except digestible energy, were measured

primer $\quad \mathrm{F}$ (5'-CCGGAATTCACCTTGGTGGATCCTGAACG-3') and reverse primer R (5'-TTGCGGCCGCAGATAAATCTTCTTCAAACGC-3') supplemented with EcoR I/Not I restriction sites. The PCR reaction was performed according the manufacturers' instructions of $2 \times$ PCR Solution Premix Taq ${ }^{\text {TM }}$ (Takara, Japan). The amplified PCR products were collected and purified by a DNA Fragment Purification Kit (Takara, Dalian, China). Then the amplified products of PBD114 by PCR were directly cloned into the pMD19-T Simple Vector, positive clones were identified by colony PCR and sequenced by Sangon
Biotech (Shanghai, China). Sequence alignment of PBD114 from TP and DLY were performed by DNAMAN 8.0, and phylogenetic tree of beta defensin 114 among human, Sus scrofa, Bos indicus and Pan troglodytes was analyzed with DNAMAN 8.0. Quantitative real-time PCR was performed on the ABI PRISM 7500 Fast Sequence Detection System for ninety-six well plates (Applied Biosystems) using the SYBR green $2 \times$ RT-PCR mix (Takara, Dalian, China). The primers of $\beta$ actin, TNF $\alpha$ and PBD114 are shown in Table 2, and the gene $\beta$-actin was used as a housekeeping gene. The relative gene expressions compared with the housekeeping gene $\beta$-actin were calculated by $2^{-\mathrm{CT}}[15]$.

\section{Preparation of rPBD114}

Gene PBD114 (without signal peptide) was synthesized by TsingKe (Beijng, China) and inserted into expression vector $\mathrm{pET} 32 \mathrm{a}(+)$ to construct recombinant expression vector pET32a(+)-PBD114. The construction of the engineered strain E. coli Origami B (DE3)-pET32a(+)-PBD114, induction of recombinant engineered strain and SDS-PAGE were performed according previous study [16], the engineered strain E. coli Origami B (DE3)-pET32a(+) was used as negative control. Identification was carried out through mass spectrometry (MALDI-TOF/TOF) by Beijing Genomics Institute. Purification of recombinant PBD114 protein (rPBD114) referred to our previous study [16]. Briefly, the supernatant with crude rPBD114 was applied to $\mathrm{Ni}^{2+}$ IDA column (Sangon Biotech, Shanghai, China) and purified according specification. Ten resin volumes of Binding Buffer ( $50 \mathrm{mmol} / \mathrm{L} \mathrm{NaH}{ }_{2} \mathrm{PO}_{4}, 300 \mathrm{mmol} / \mathrm{L} \mathrm{NaCl}, \mathrm{pH}$ 8.0) were added to wash way the impure protein, and then five resin volumes of Elution Buffer $\left(50 \mathrm{mmol} / \mathrm{L} \mathrm{NaH} \mathrm{NO}_{4}\right.$, $300 \mathrm{mmol} / \mathrm{L} \mathrm{NaCl}, 150 \mathrm{mmol} / \mathrm{L}$ imidazole, $\mathrm{pH} \mathrm{8.0)}$ were added to eluted the rPBD114 from the column. The protein concentration was determined by the BCA assay (Beyotime, Shanghai, China). The purifed rPBD114 was electrophoresed on a $12 \%$ SDS-PAGE gel. The rest was stored at $-80^{\circ} \mathrm{C}$ to analyze biological activities.

\section{Structure homology-modelling and physical and chemical parameters of PBD114}

The automated protein structure homology-modelling of PBD114 was performed by SWISS-MODEL online (https://swissmodel.expasy.org/) to predict the structure of PBD114. The computation of various physical and chemical parameters for PBD114 carried out by ExPASy online (https://web.expasy.org/protparam/) to predict theoretical pI, net charged residues and aliphatic index of PBD114.

\section{Minimal inhibitory concentration}

The minimal inhibitory concentration (MIC) for antimicrobial activity analysis of purified rPBD114 was measured by 
Table 2 Primers sequences used for quantitative RT-PCR

\begin{tabular}{llll}
\hline Gene & Accession No. & Primer sequences $\left(5^{\prime} \rightarrow 3^{\prime}\right)$ & Product length, bp \\
\hline B-actin & XM_003124280.5 & TGGAACGGTGAAGGTGACAGC & 177 \\
& & GCTITGGGAAGGCAGGGACT & 173 \\
TNFa & NM_214022.1 & GCATCGCCGTCTCCTACCAG & 130 \\
& & GGGCAGGTTGATCTCGGCAC & 114 \\
& NM_001129973.1 & TTGGTGGATCCTGAACGATGCT & \\
\hline
\end{tabular}

the microtiter broth dilution method [17]. E. coli DH5 pathogenic E. coli $\mathrm{K} 88+$, S. typhimurium, S. aureus, B. subtilis were grown to $0.4 \mathrm{OD}_{600}$ at $37^{\circ} \mathrm{C}$ in LB, Streptococcus was grown to $0.4 \mathrm{OD}_{600}$ at $37^{\circ} \mathrm{C}$ in THY (Todd-Hewit$\mathrm{t}+$ yeast extract), Pichia pastoris $\mathrm{X}_{33}$ was grown to 0.4 $\mathrm{OD}_{600}$ at $37^{\circ} \mathrm{C}$ in YPD. The target cell culture was diluted to $1 \times 10^{5} \mathrm{CFU} / \mathrm{mL}$ with same media respectively. A total of $100 \mu \mathrm{L}$ of $\mathrm{rPBD} 114$ and $100 \mu \mathrm{L}$ of cell suspension were added into each well. The activity of rPBD114 was tested over a concentration range of $256,128,64,32,16,8,4,2,1$, 0.5 and $0.25 \mu \mathrm{g} / \mathrm{mL}$, and all assays were tested in triplicated. Bacterial plates were incubated at $37^{\circ} \mathrm{C}$ for $16 \mathrm{~h}$, fungal plate was incubated at $30^{\circ} \mathrm{C}$ for $24 \mathrm{~h}$, and the absorption of cell culture was recorded at $600 \mathrm{~nm}$. MIC was defined as the lowest concentration of peptide at which there was no change in optical density.

\section{Hemolytic activity assay}

The hemolytic activity of rPBD114 was measured spectrophotometrically using a hemoglobin release assay [18]. Fresh pig blood was collected to prepare erythrocytes by centrifugation at $1500 \mathrm{r} / \mathrm{min}$ for $10 \mathrm{~min}$ at room temperature. The erythrocytes were gently washed three times with PBS ( $\mathrm{pH} 7.2)$ and resuspended to $4 \%(v / v)$ with PBS (pH 7.2). 4\% erythrocytes were incubated with different concentrations $(0.5 \sim 256 \mu \mathrm{g} / \mathrm{mL}$, double gradient) of rPBD114 for $1 \mathrm{~h}$ at $37^{\circ} \mathrm{C}$, and then centrifuged at $1000 \mathrm{r} / \mathrm{min}$ for $5 \mathrm{~min}$. Three $\mathrm{mL}$ supernatant were then added to a 2-cm quartz cuvette, and the absorbance was measured at $414 \mathrm{~nm}$ with UV-1100 spectrophotometer (ShangHai, China). No hemolysis and 100\% hemolysis were determined in PBS and Triton X-100, respectively.

\section{Cytotoxicity assay}

The cytotoxicity of rBPD114 was measured according to previously a study [19]. Briefly, IPEC-J2 cells were cultured in DMEM-F12 with $10 \% \mathrm{FBS}, 100 \mathrm{U} / \mathrm{mL}$ penicillin, and $100 \mu \mathrm{g} / \mathrm{mL}$ streptomycin for $48 \mathrm{~h}$ and then resuspended to $10^{5}$ cells $/ \mathrm{mL}$ in FBS free DMEM-F12 media. A volume of $100 \mu \mathrm{L}$ of cells was aliquoted into sterile flat-bottomed 96-well plates (Corning, USA). Final concentration of $0,4,16,64$ and $256 \mu \mathrm{g} / \mathrm{mL}$ rPBD114 were added to the cells and incubated at $37{ }^{\circ} \mathrm{C} / 5 \% \mathrm{CO}_{2}$ for 24 $h$. Cell viability was evaluated with the CCK-8 assay (Beyotime, Shanghai, China) according to the manufacturer's instructions.

\section{Statistical analysis}

All of the statistical analyses were performed using Graphpad Prism 7.0. Differences in PBD114 expression among breeds were investigated using Student's $t$-test (and nonparametric tests). Treatment differences of PBD114 expression of IPEC-J2 and cytotoxicity were statistically analyzed by One-way ANOVA, Tukey's test was applied post hoc. Data were expressed as the mean \pm standard error of the mean. Values in the same row with different superscripts are significant $(P<0.05)$, while values with same superscripts are not significant different $(P>0.05)$.

\section{Results}

\section{Expression profiles of PBD114 gene in different pig} breeds and tissues

To evaluate expression profiles of PBD114, mRNA expressions in various tissues among TP (Fig. 1a) and DLY (Fig. 1b) were measured. PBD114 widely expressed in duodenum, jejunum, ileum, cecum, colon, liver, spleen, kidney, lung and thymus, while the tissue with the highest expression abundance was jejunum in TP and duodenum of DLY. The different expression levels of PBD114 between TP pigs and DLY pigs were display in Fig. 1c. The results showed that the expression levels of PBD114 of TP pigs in jejunum, colon and lung were higher than DLY pigs $(P<0.05)$. However, the abundance of PBD114 of TP pigs in kidney were lower than DLY pigs $(P<0.05)$.

\section{Expression profiles of PBD114 gene upon E. coli K88 challenge}

The effects of E. coli $\mathrm{K} 88$ on the expression of PBD114 were displayed in Fig. 2. Diarrhea scores of K88 group were higher than CON group over $24 \mathrm{~h}$ except at $20 \mathrm{~h}$ $(P<0.05)$, and the results indicated that $E$. coli K88 challenged model was successful. In vivo, the expressions of 

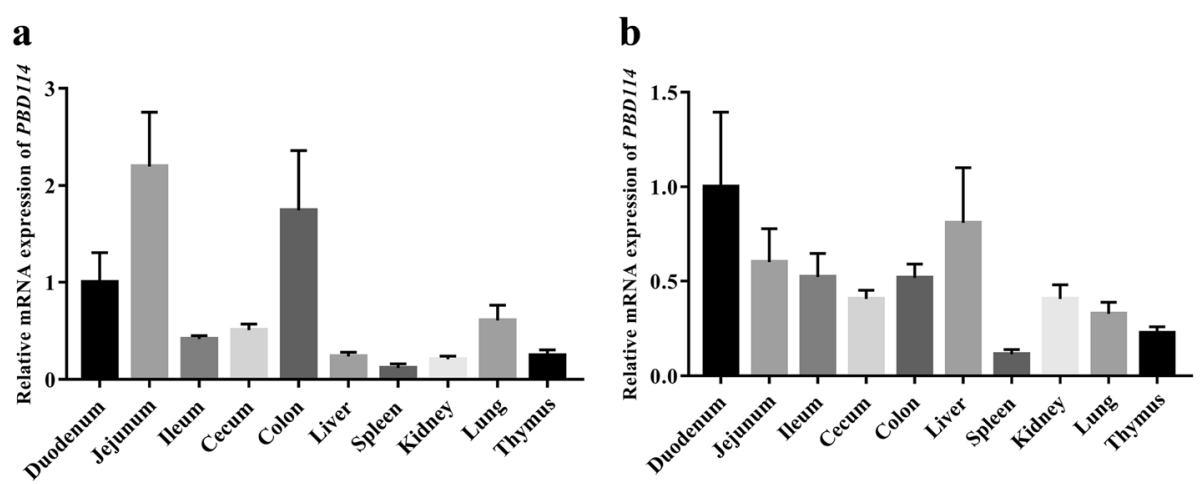

c

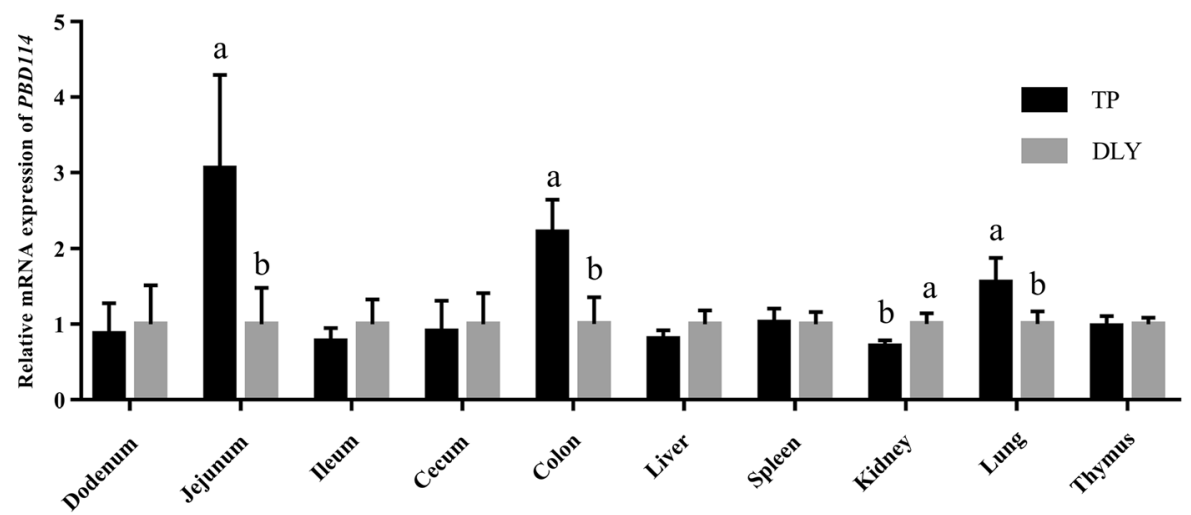

Fig. 1 The mRNA level of PBD114 in Tibetan and DLY pigs. a, the mRNA level of PBD114 in tissues of Tibetan pigs; $\mathbf{b}$, the mRNA level of PBD114 in tissues of DLY pigs; $\mathbf{c}$, comparison of the mRNA level of PBD114 among breeds. Values are means $\pm S E, n=6$. ${ }^{a}$, b Mean in a same column with different superscripts differ significantly $(P<0.05)$

$P B D 114$ in duodenum, jejunum and ileum were significantly induced by $E$. coli $\mathrm{K} 88(P<0.05)$. In vitro, the expressions of TNF $\alpha$ in IPEC-J2 were markedly increased by $1 \times 10^{5}$ and $1 \times 10^{6} \mathrm{CFU} / \mathrm{mL}$ E. coli $\mathrm{K} 88$, and $1 \times 10^{5}$ $\mathrm{CFU} / \mathrm{mL}$ E. coli $\mathrm{K} 88$ also obviously induced the expression of PBD114 $(P<0.05)$.

\section{Cloning and sequence analysis of the PBD114 gene}

In order to compare the homology of PBD114 between TP pigs and DLY pigs, the 210-bp open reading frame of PBD114 from TP pigs and DLY pigs were successfully amplified (Additional file 1: Figure S1). Then PBD114 amplicons from TP and DLY pigs were cloned and sequenced, and the results of sequence alignment indicated that DNA sequence identity of PBD114 between TP and DLY pigs was identical with NM_001129973.1 (Fig. 3a). Amino acid sequence identity and phylogenetic tree of beta defensin 114 among Homo sapiens, Sus scrofa, Bos indicus and Pan troglodytes was compared. Phylogenetic tree analysis results indicated that beta defensin 114 of Sus scrofa was close to Homo sapiens (Fig. 3b). Moreover, with $45.83 \%$ amino acid sequence identity of beta defensin 114 from human and Sus scrofa (Fig. 3c).

\section{Expression and purification of rPBD114}

The recombinant strain E. coli Origami B (DE3)pET32a(+)-PBD114 and E. coli Origami B (DE3)pET32a $(+)$ were constructed, and positive colonies were identified by colony PCR (data were not showed). And then the identified positive colony was cultured and induced by $1 \mathrm{mmol} / \mathrm{L}$ isopropyl- $\beta$-d-thiogalactoside (IPTG) at $28^{\circ} \mathrm{C}$ for $9 \mathrm{~h}$. Then SDS-PAGE analysis showed that the target protein with the Trx tag conformed to the theoretical molecular weight (Fig. 4), of $25.18 \mathrm{kDa}$. The pellets were disrupted with sonication and dissolved in lysis buffer. The crude soluble recombinant protein was purified by $\mathrm{Ni}^{2+}$-IDA affinity chromatography. SDS-PAGE was performed and the purity of rPBD114 was analyzed with Image Lab (Bio-Rad). The result showed that the purity of rPBD114 was 95\% and the expression level of rPBD114 was $5.0 \mathrm{mg} / \mathrm{L}$. The target band was collected and amino acid sequence of rPBD114 was identified by mass spectrometry (MALDI-TOF/TOF) (Fig. 5a). Through searching uniprot-Sus-scrofa (68,152 sequences, 25,615,784 residues), rPBD114 sequence had a $100 \%$ math with $\mathrm{NP}_{-}$ 001123445 (Fig. 5b), more MS information was shown in Additional file 2 data. 

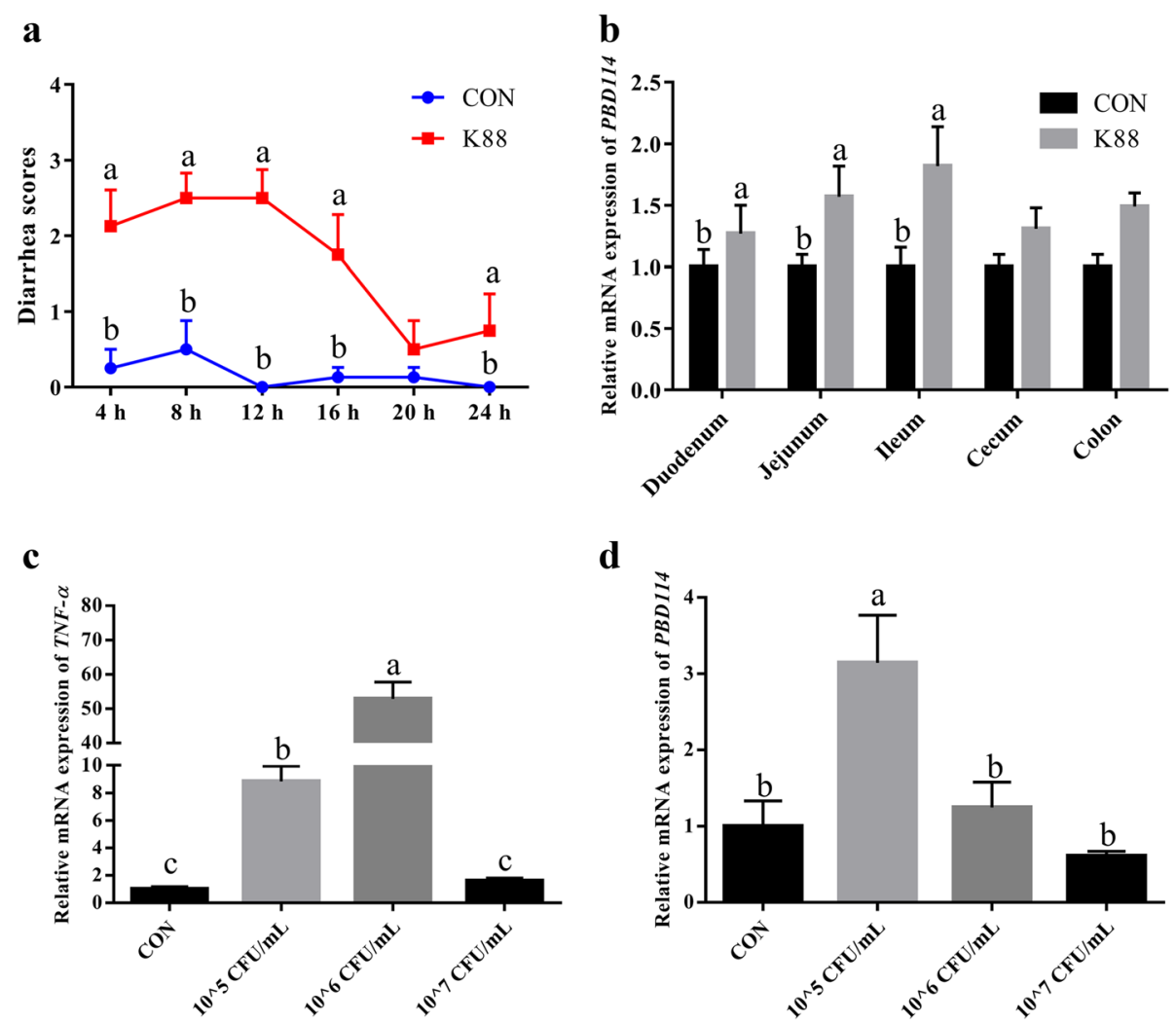

Fig. 2 Escherichia coli K88 induced the expression of PBD114 in 6 days old pigs and IPEC-J2. a, diarrhea scores of 7 days old piglets challenged by E. coli K88 or not; $\mathbf{b}$, effects of $E$. coli K88 challenge on the mRNA level of PBD114 in intestinal tissues; Effects of $E$. coli K88 challenge on the mRNA level of TNFa (c) and PBD114 (d) in IPEC-J2. Values are means $\pm \mathrm{SE}, n=8 .{ }^{\text {a, }}$, c Mean in a same column with different superscripts differ significantly $(P<0.05)$

\section{Protein structure, physical and chemical parameters of PBD114}

Protein structure prediction was performed online to explore the biological function of PBD114. SWISSMODEL analysis found that the structure of PBD114 was similar to human beta defensin 2 with $35.14 \%$ sequence identity (Additional file 1: Figure S2). The predicted structure of PBD114 indicated that PBD114 was consisted of an alpha helix fragment and a $\beta$-pleated sheet fragment (Additional file 1: Figure S2), the detail predicted results were provided in Additional file 1: Figure S3. Physical and chemical parameters of PBD114 was analyzed by ProtParam online, theoretical pI, net charged residues and aliphatic index of PBD114 was $7.46,+1$ and 66.38 respectively, and more information was shown in Additional file 3 data.

\section{Antibacterial activities}

The antimicrobial activity of rPBD114 was explored by determining its $\mathrm{MIC}$ against $E$. coli $\mathrm{DH} 5 \alpha$, pathogenic E. coli $\mathrm{K} 88+$, S. typhimurium, S. aureus, B. subtilis and Pichia pastoris $\mathrm{X}_{33}$ (Table 3 ). The results showed that rPBD114 exhibited strong antimicrobial activity against E. coli $\mathrm{DH} 5 \alpha$ and pathogenic E. coli $\mathrm{K} 88+$, The MIC value of $E$. coli $\mathrm{DH} 5 \alpha$ and pathogenic E. coli $\mathrm{K} 88+$ were 64 and $128 \mu \mathrm{g} / \mathrm{mL}$ respectively. However, much higher concentration rPBD114 (more than $256 \mu \mathrm{g} / \mathrm{mL}$ ) were needed to against $S$. typhimurium, S. aureus, B. subtilis and Pichia pastoris X33. The tolerance of these four organisms to rPBD114 indicate that Pichia pastoris X33 would be more tolerant to expression of rPBD114.

\section{Hemolytic activity and cytotoxicity assays}

Erythrocytes were collected from fresh porcine blood and incubated with different concentrations of rPBD114 for $1 \mathrm{~h}$. Less than $3.9 \%$ hemolysis was found at all concentrations $(0-256 \mu \mathrm{g} / \mathrm{mL})$. The results showed that rPBD114 had slight hemolytic in vitro (Fig. 6a). IPEC-J2 was also used to examine cytotoxicity of rPBD114, cell viability was measured by CCK- 8 after treating with different concentrations of rPBD114. There was little cytotoxicity (Fig. 6b) when the concentration of rPBD114 was less than $256 \mu \mathrm{g} / \mathrm{mL}$. However, the cytotoxicity was significant when the concentration of rPBD114 was $256 \mu \mathrm{g} / \mathrm{mL}(P<0.05)$. These results suggested that the safe concentration of rPBD114 should be lower than $256 \mu \mathrm{g} / \mathrm{mL}$. 


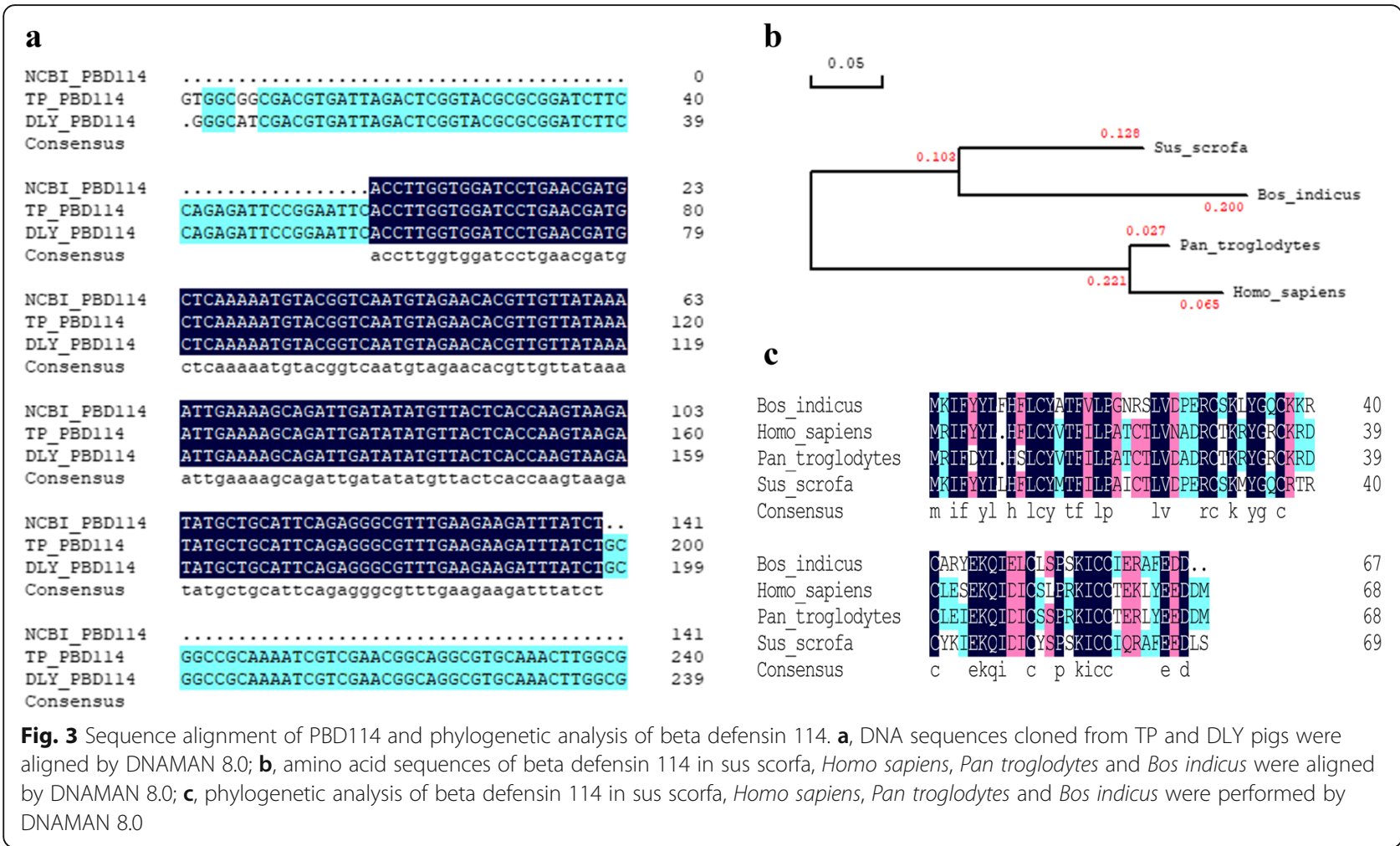

\section{Discussion}

The innate and adaptive immunity are two essential elements of host defense. Innate immunity is highly conserved from fruit flies to human and is the first line of defense against invading pathogens. One mechanism of

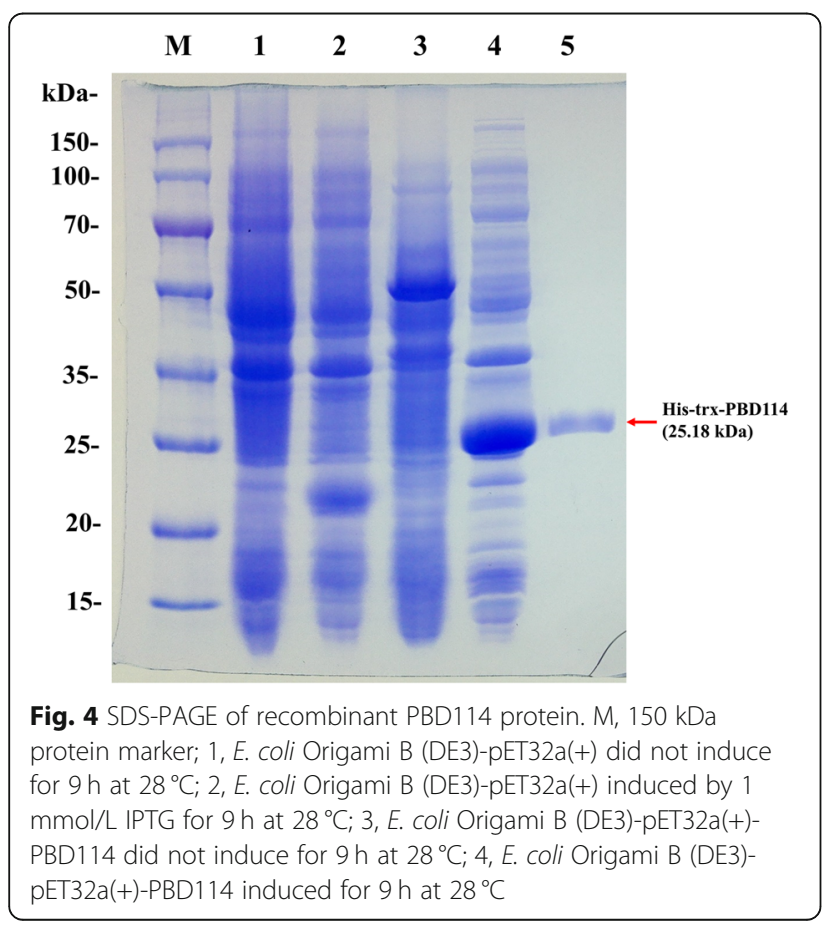

the innate immunity is the secretion of broad-spectrum antimicrobial substances, such as cathelicidins and small cationic polypeptides named defensins [20]. Previous studies reported that porcine $\beta$-defensin 1 and $\beta$ defensin 2 existed broad-spectrum antimicrobial activities and immune modulating function [20]. Human beta defensin 114 exhibited strong antimicrobial activity against E. coli, C. albicans and S. aureus, and antiinflammatory function [21]. Choi et al. [13] found PBD114 by a BLAST analysis in 2012. However, the expression profile of PBD114 in various tissues of pigs and biological function of PBD114 have not been studied. Therefore, the present study was conducted to explore the expression profiles of the PBD114 in different breeds and in response to infections. Moreover, the function of PBD114 protein has also been investigated.

Our results showed that PBD114 widely expressed in duodenum, jejunum, ileum, cecum, colon, liver, spleen, lung, kidney and thymus, in both TP and DLY pigs. Similar expression patterns also have been demonstrated by previous study on porcine beta defensins [13]. The extensive expression of PBD114 suggested that this endogenous peptide antibiotic may contribute to both mucosal and systemic host defenses in pigs. Chinese TP is a special Chinese indigenous pig breed, which are distributed in high-altitude areas of Qinghai-Tibet Plateau which has cold climate. They are raised in pollution-free, purely natural alpine and cold mountainous areas all 


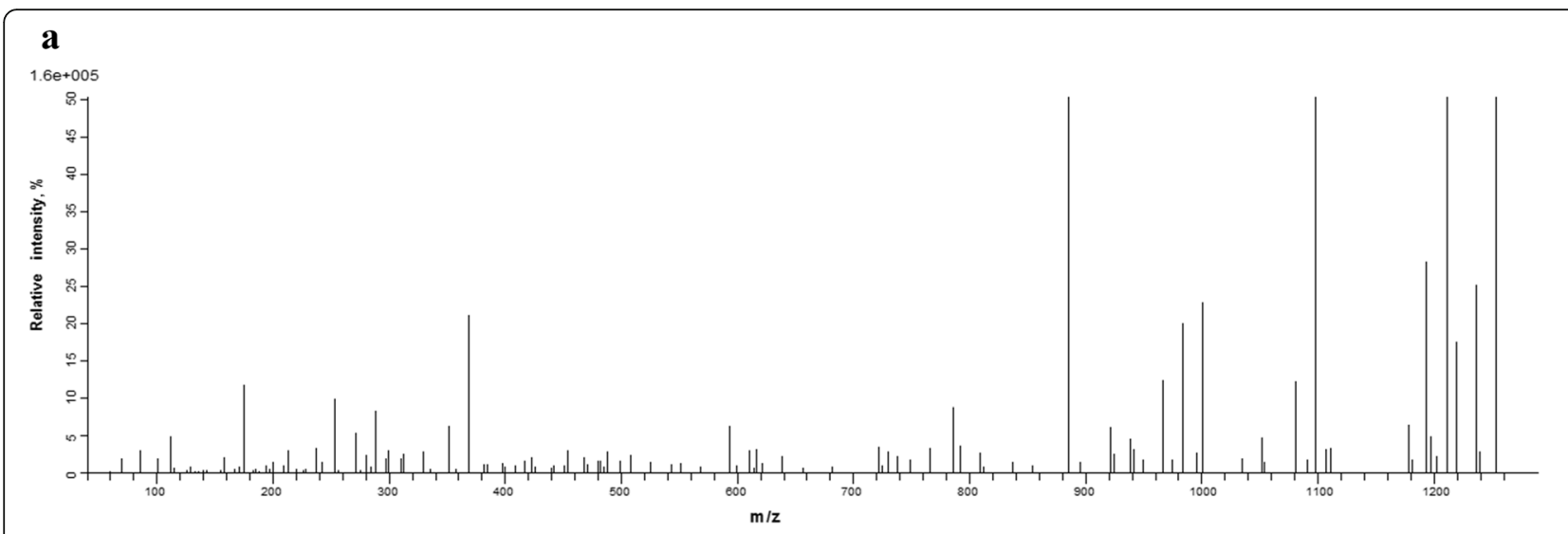

b

\section{MKIFYYLLHF LCYMTFILPA ICTLVDPERC SKMYGQCRTR CYKIEKQIDI CYSPSKICCI QRAFEEDLS}

Fig. 5 Mass spectrometry identification of rPBD114. a, peak figure of amino acid fragments; b, through searching uniprot-Sus-scrofa (68152 sequences, 25615784 residues), rPBD114 sequence had a 100\% math with NP_001123445 (show in red)

year round. And their immunity and disease resistance are stronger than Duroc pigs [22, 23]. The higher level mRNA of PBD114 was detected in intestine of TP and DLY pigs, furthermore, the results of comparison among breeds showed that the abundance of PBD114 mRNA of TP pigs in jejunum, colon and lung were higher than DLY pigs. As well, defensins are a family of endogenous cationic antimicrobial peptides that play an important role in the innate immune system of mammals and provide protection against bacterial infections in the intestine $[24,25]$, Hence, the high expression of PBD114 in TP pigs may have implications for the contribution of PBD114 on high disease resistance of TP, and which was the same as PBD1, 2 and $3[22,26]$.

Due to the impact of thousands of years of artificial selection for survival of these breeds of different signatures of selection in TP and domestic pigs [23], we chose to investigate whether there were some variants in the PBD114 gene. So the DNA sequence of PBD114 was

Table 3 MIC of rPBD114

\begin{tabular}{ll}
\hline Strain & $r P B D-114, \mu \mathrm{g} / \mathrm{mL}$ \\
\hline Gram-netative bacteria & 64 \\
E. coli DH5a & 128 \\
Pathogenic E. coli K88+ & $>512$ \\
Salmonella typhimurium ATCC14028 & \\
Gram-positive bacteria & $>512$ \\
Streptococcus & $>512$ \\
Staphylococcus aureus CICC10384 & $>512$ \\
Bacillus subtilis & \\
Fungi & 512 \\
Pichia pastoris $\mathrm{X}_{33}$ & \\
\hline
\end{tabular}

cloned from TP and DLY pigs respectively. Agarose gel electrophoresis of cloning PCR showed that the size of PBD114 from TP and DLY pigs was same to theoretical value $(210 \mathrm{bp})$. Further DNA sequence alignment of PBD114 between TP and DLY pigs indicated that the identity was $100 \%$, and exactly consistent with $\mathrm{NM}_{-}$ 001129973.1 in NCBI. The sequence of gene PBD114 did not mutated during thousands evolutionary history, and this hinted that PBD114 was very important to survive and breed of pigs. Moreover, previous study reported that human defensin 114 exhibited a broad spectrum of antimicrobial activity with Escherichia coli, Staphylococcus aureus and Candida albicans [27]. Amino acid sequence alignment of beta defensin 114 between pig and human showed that the identity was $45.83 \%$, and phylogenetic analysis was performed with amino acid of Sus scrofa, Homo sapiens, Pan troglodytes and Bos indicus, and showed that PBD114 was closely related to DEFB114. These results suggested that PBD114 may possess antimicrobial activity like DEFB114.

To explore whether PBD114 take part in resistance to pathogens, we carried out experiments in vitro and in vivo. The results showed that $E$. coli K88 significantly induced the expression of PBD114 in vitro and in vivo. On the one hand, the results indicated that PBD114 was an inducible defensin. According previous studies, PBD114 was not only induced by $E$. coli $\mathrm{K} 88$, but also could be promoted by nutrients and probiotics $[27,28]$. On the other hand, PBD114 may play an important role in killing E. coli $\mathrm{K} 88$ or immune modulating function to alleviate the damage of $E$. coli K88. Because previous study reported that DEFB114 (a human homologous protein of PBD114) not only exhibited antimicrobial activity but also could inhibit RAW264.7 release TNF $\alpha$ 


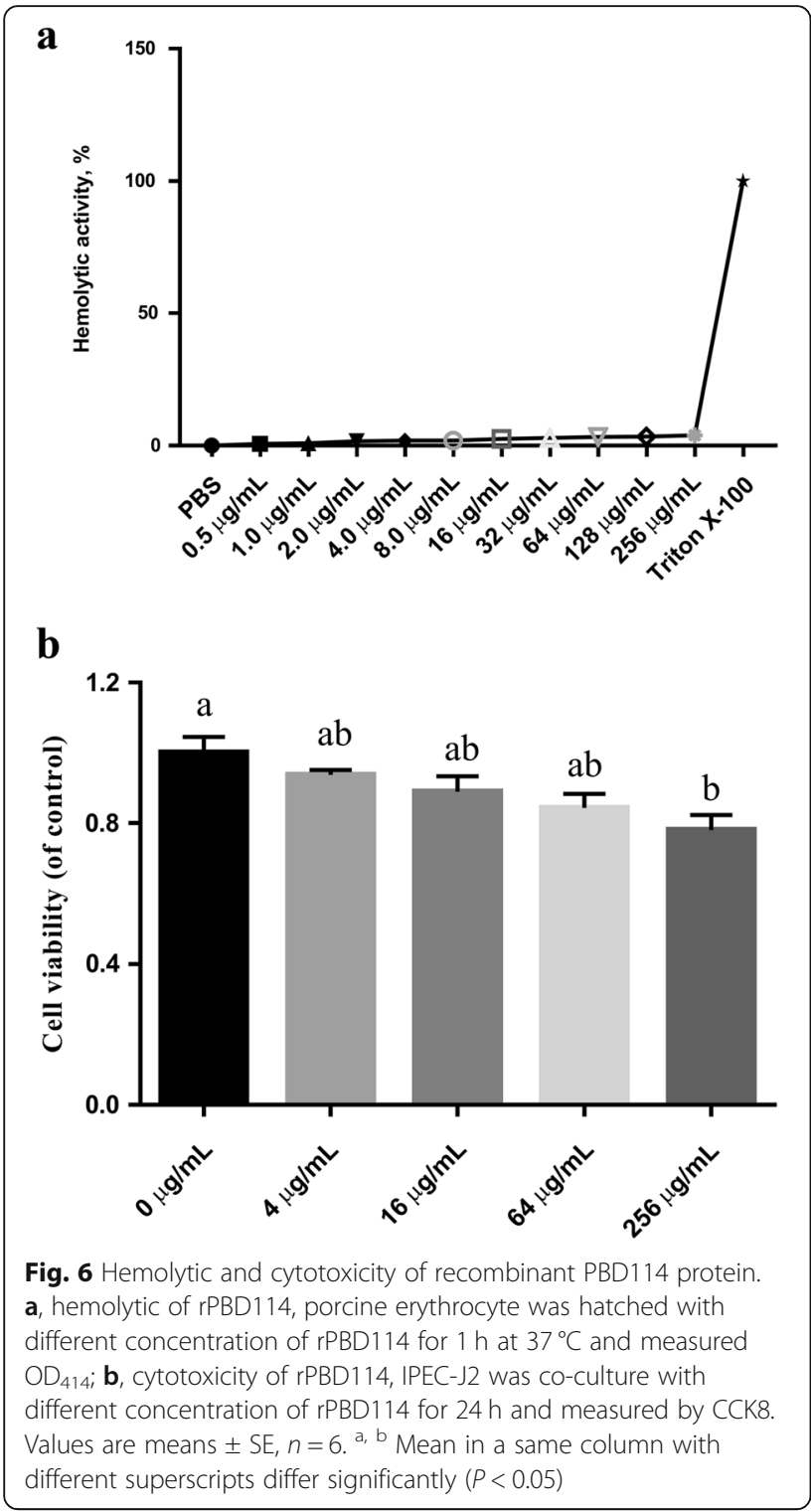

after stimulation with LPS [26]. In addition, PBD2 protected intestinal health via modulating of $\mathrm{TJ}$ proteins in intestine and inhibiting the production of inflammatory mediators [29].

To explore the antimicrobial activity of PBD114, PBD114 was expressed in an Escherichia coli expression system. Because Escherichia coli expression system technology was mature and simple, still the first choice as host for AMPs production $[16,30]$. In addition, PBD114 possessed three disulfide bonds, so we selected $\mathrm{pET} 32 \mathrm{a}(+)$ and $E$. coli Origami B (DE3) to construct recombinant expression bacteria. pET32a(+) vector possessed thioredoxin tag which can increase the activity and amount of target protein present in the soluble fraction. E. coli Origami B (DE3) with glutathione reductase (gor) and/or thioredoxin reductase (trxB) mutations enhance the formation of disulfide bonds in the
E. coli cytoplasm [31]. We successfully constructed recombinant bacteria, E. coli Origami B (DE3)-pET32a (+)-PBD114 and expressed the rPBD114 protein. rPBD114 was identified by mass spectrometry and the sequence coverage 100\% was identical to NP_001123445. Physical and chemical parameters showed that rPBD114 possessed positive net charge $(+1)$, aliphatic index (66.38) and grand average of hydropathicity $(-0.530)$, and suggested that PBD114 protein has the biochemical properties of antimicrobial peptides [32]. As we all know, protein structure determines protein function. To learn more about the function of PBD114 protein, we predicted the protein structure of PBD114 protein on SWISS-MODEL and the results showed that the structure of PBD114 protein was similar with human defensin 2 . Human beta defensin 2 is produced by a number of epithelial cells and exhibits potent antimicrobial activity against Gram-negative bacteria and Candida, but not Gram-positive Staphylococcus aureus [33]. Similarly, MIC of rPBD114 protein was carried out and rPBD114 protein exhibited antimicrobial activity against E. coli but not Gram-positive bacteria and fungus. However, a great number of studies have shown that defensins have a wide range of antimicrobial activities [34-37]. The antimicrobial activity of rPBD114 protein in our study suggested that Pichia pastoris $\mathrm{X}_{33}$ would be more tolerant to expression of rPBD114. The methylotrophic yeast Pichia pastoris can grow to extremely high cell densities, enabling efficient protein production and secretion [38, 39]. The most attractive feature of this system is that the recombinant protein could be exactly folded, fully decorated and easily purified [40]. However, the yeast may have been more resistant to the defensins if it were not properly processed. Therefore, further study in Pichia pastoris was needed. In addition, hemolytic and cytotoxicity of rPBD114 protein indicated that rPBD114 was safe to mammals. These results suggested that rPBD114 may serve as a candidate for the replacement of conventionally used antibiotics. However, further researches are needed to investigate such as the structural and functional analysis, immunogenicity, and biologic function of rPBD114 protein in vitro and in vivo.

\section{Conclusions}

$P B D 114$ is an infection response gene that is differentiallyexpressed between different porcine breeds and tissues. The antimicrobial activity of PBD114 protein, against pathogens such as the E. coli K88, few hemolytic activity and cytotoxicity suggested that it may serve as a candidate for the substitution for conventionally used antibiotics.

\section{Additional files}

Additional file 1: $\mathrm{PBD} 114$ cloning PCR and predictive spatial structure of rPBD114. (DOCX $840 \mathrm{~kb})$ 
Additional file 2: Detail information of MS. (XLSX 9 kb)

Additional file 3: Detail information of physicochemical. (DOCX 19 kb)

\section{Abbreviations}

AMPs: Antimicrobial peptides; DEFB114: Human beta defensin 114; DLY: DurocXLandrancexYorkshire; IPTG: Isopropyl- $\beta$-d-thiogalactoside: LB: Lysogeny broth; LPS: Lipopolysaccharide; MALDI-TOF/TOF: Matrix-assisted laser desorption/ionization time of flight mass spectrometry; MIC: Minimal inhibitory concentration; PBD114: Porcine beta defensin 114; rPBD114: Recombinant porcine beta defensin 114; SDS-PAGE: Sodium dodecyl sulfate polyacrylamide gel electrophoresis; THY: Todd-Hewitt+yeast extract; TJ: Tight junction; TP: Tibetan pig; YPD: Yeast Extract Peptone Dextrose Medium

\section{Acknowledgements}

We thank Honglin Yan, Weikang Wang, Qian Lin and Yaqiang Dai for assistance in collecting samples of TP pigs, and thank Huifen Wang and Quyuan Wang for purchasing consumables and reagents.

\section{Authors' contributions}

$J H, J L, J Y, P Z, X M, Y L, Z H, B Y$ and DC participated in the design of the study. QS, KX and QL collected the experiments data. GS analyzed the data and wrote the first draft of the manuscript. All authors read and approved the final manuscript.

\section{Funding}

This work was supported by the Key Research and Development Program of Sichuan Province (2018NZDZX0005), and the Youth Innovation Teams of Animal Feed Biotechnology of Sichuan Province (2016TD0028).

\section{Availability of data and materials}

The datasets during and/or analyzed during the current study are available from the corresponding authors on reasonable request.

\section{Ethics approval and consent to participate}

The experimental procedures followed the actual law of animal protection that were approved by the Animal Care Advisory Committee of Sichuan Agricultural University (No. 20160709) and were performed in accordance with the National Research Council's Guide for the Care and Use of Laboratory Animals.

\section{Consent for publication}

All authors read and approved the final manuscript.

\section{Competing interests}

The authors declare that they have no competing interests.

Received: 1 February 2019 Accepted: 22 May 2019

Published online: 19 July 2019

\section{References}

1. Veldhuizen EJ, Rijnders M, Claassen EA, van Dijk A, Haagsman HP. Porcine beta-defensin 2 displays broad antimicrobial activity against pathogenic intestinal bacteria. Mol Immunol. 2008;45:386-94.

2. Zhu YG, Johnson TA, Su JQ, Qiao M, Guo GX, Stedtfeld RD, et al. Diverse and abundant antibiotic resistance genes in Chinese swine farms. Proc Natl Acad Sci U S A. 2013;201222743.

3. Auvynet C, Rosenstein Y. Multifunctional host defense peptides: antimicrobial peptides, the small yet big players in innate and adaptive immunity. FEBS J. 2009;276:6497-508.

4. Yang D, Liu ZH, Tewary P, Chen Q, de la Rosa G, Oppenheim JJ. Defensin participation in innate and adaptive immunity. Curr Pharm Des. 2007;13:3131-9.

5. Selsted ME, Ouellette AJ. Mammalian defensins in the antimicrobial immune response. Nature Immunol. 2005;6:551

6. Zhang G, Wu H, Shi J, Ganz T, Ross CR, Blecha F. Molecular cloning and tissue expression of porcine beta-defensin-1. FEBS Lett. 1998;424:37-40.

7. Salzman NH, Hung K, Haribhai D, Chu H, Karlsson-Sjöberg J, Amir E, et al. Enteric defensins are essential regulators of intestinal microbial ecology. Nature Immunol. 2009;11:76.
8. Zhang Y, Teng D, Mao R, Wang X, Xi D, Hu X, et al. High expression of a plectasin-derived peptide NZ2114 in Pichia pastoris and its pharmacodynamics, postantibiotic and synergy against Staphylococcus aureus. Appl Microbiol Biotechnol. 2014;98:681-94.

9. Cohen ML. Changing patterns of infectious disease. Nature. 2000;406:762-7.

10. Elahi S, Buchanan RM, Attah-Poku S, Townsend HG, Babiuk LA, Gerdts V. The host defense peptide beta-defensin 1 confers protection against Bordetella pertussis in newborn piglets. Infect Immun. 2006;74:2338-52.

11. Li CL, Xu TT, Chen RB, Huang XX, Zhao YC, Bao YY, et al. Cloning, expression and characterization of antimicrobial porcine beta defensin 1 in Escherichia coli. Protein Expr Purif. 2013;88:47-53.

12. Veldhuizen EJA, Dijk AV, Tersteeg MHG, Kalkhove SIC, Meulen JVD, Niewold TA, et al. Expression of $\beta$-defensins pBD-1 and pBD-2 along the small intestinal tract of the pig: lack of upregulation in vivo upon Salmonella typhimurium infection. Mol Immunol. 2007:44:276-83.

13. Choi MK, Le MT, Nguyen DT, Choi H, Kim W, Kim JH, et al. Genome-level identification, gene expression, and comparative analysis of porcine Bdefensin genes. BMC Genet. 2012;13:98

14. Kusminski CM, Park J, Scherer PE. MitoNEET-mediated effects on browning of white adipose tissue. Nat Commun. 2014;5:3962.

15. Livak KJ, Schmittgen TD. Analysis of relative gene expression data using real-time quantitative PCR and the 2(-Delta Delta C(T)) method. Methods. 2001;25:402-8.

16. Su G, Tang F, Chen D, Yu B, Huang Z, Luo Y, et al. Expression, purification and characterization of a novel antimicrobial peptide: Gloverin A2 from Bombyx mori. Int J Pept Res Ther. 2018:1-7.

17. Zhang J, Yang YL, Teng D, Tian ZG, Wang SR, Wang JH. Expression of plectasin in Pichia pastoris and its characterization as a new antimicrobial peptide against Staphyloccocus and Streptococcus. Protein Expres Purif. 2011;78:189-96.

18. Feng X, Liu C, Guo J, Song X, Li J, Xu W, et al. Recombinant expression, purification, and antimicrobial activity of a novel hybrid antimicrobial peptide LFT33. Appl Microbiol Biotechnol. 2012;95:1191-8.

19. Deng X, Cao M, Zhang J, Hu K, Yin Z, Zhou Z, et al. Hyaluronic acid-chitosan nanoparticles for co-delivery of MiR-34a and doxorubicin in therapy against triple negative breast cancer. Biomaterials. 2014;35:4333-44.

20. Qi S, Chen J, Guo R, Yu B, Chen D. B-Defensins gene expression in tissues of the crossbred and Tibetan pigs. Livest Sci. 2009;123:161-8.

21. Yu H, Dong J, Gu Y, Liu H, Xin A, Shi H, et al. The novel human $\beta$-defensin 114 regulates lipopolysaccharide (LPS)-mediated inflammation and protects sperm from motility loss. J Biol Chem. 2013;288:12270-82.

22. Zhao Y, Yu B, Mao XB, Han GQ, Mao Q, Huang ZQ, et al. Molecular cloning and expression analysis of IFN- $\beta$ promoter stimulator 1 in Tibetan pigs. Mol Biol Rep. 2012;39(6):7011-7.

23. Li M, Tian S, Jin L, Zhou G, Li Y, Zhang Y, et al. Genomic analyses identify distinct patterns of selection in domesticated pigs and Tibetan wild boars. Nat Genet. 2013;45:1431.

24. Veldhuizen EJA, Koomen I, Ultee T, van Dijk A, Haagsman HP. Salmonella serovar specific upregulation of porcine defensins 1 and 2 in a jejunal epithelial cell line. Vet Microbiol. 2009;136:69-75.

25. Ganz T. Defensins and other antimicrobial peptides: a historical perspective and an update. Comb Chem High T Scr. 2005:8:209-17.

26. Chen J, Qi S, Guo R, Yu B, Chen D. Different messenger RNA expression for the antimicrobial peptides beta-defensins between Meishan and crossbred pigs. Mol Biol Rep. 2010;37:1633.

27. Ren M, Zhang SH, Zeng XF, Liu H, Qiao SY. Branched-chain amino acids are beneficial to maintain growth performance and intestinal immune-related function in weaned piglets fed protein restricted diet. Asian-Australas J Anim Sci. 2015;28:1742-50

28. Liu H, Hou C, Wang G, Jia H, Yu H, Zeng X, et al. Lactobacillus reuteri 15007 modulates intestinal host defense peptide expression in the model of IPEC$\mathrm{J} 2$ cells and neonatal piglets. Nutrients. 2017;9.

29. Han F, Zhang $H$, Xia X, Xiong H, Song D, Zong $X$, et al. Porcine betadefensin 2 attenuates inflammation and mucosal lesions in dextran sodium sulfate-induced colitis. J Immunol. 2015;194:1882-93.

30. Parachin NS, Mulder KC, Viana AAB, Dias SC, Franco OL. Expression systems for heterologous production of antimicrobial peptides. Peptides. 2012;38:446-56.

31. Prinz WA, Åslund F, Holmgren A, Beckwith J. The role of the Thioredoxin and Glutaredoxin pathways in reducing protein disulfide bonds in the Escherichia coli cytoplasm. J Biol Chem. 1997;272:15661-7.

32. Yeaman MR, Yount NY. Mechanisms of antimicrobial peptide action and resistance. Pharmacol Rev. 2003:55:27-55. 
33. Schröder JM, Harder J. Human beta-defensin-2. Int J Biochem Cell Biol. 1999; 31:645-51

34. Kahlon AK, Tripathi S, Sharma A. Chapter 8 - recent developments and future prospects of natural and synthetic Antitubercular peptide drugs. In: Amandeep KK, Shubhandra T, Ashok S, editors. Applied microbiology and bioengineering: Academic Press; 2019. p. 121-59.

35. Yang M, Zhang C, Zhang MZ, Zhang S. Beta-defensin derived cationic antimicrobial peptides with potent killing activity against gram negative and gram positive bacteria. BMC Microbiol. 2018;18:54.

36. Sun E, Belanger CR, Haney EF, Hancock REW. Host defense (antimicrobial) peptides. In: Koutsopoulos S, editor. Peptide applications in biomedicine, biotechnology and bioengineering: Woodhead Publishing; 2018. p. 253-85.

37. Chen RB, Zhang K, Zhang H, Gao CY, Li CL. Analysis of the antimicrobial mechanism of porcine beta defensin 2 against E. coli by electron microscopy and differentially expressed genes. Sci Rep. 2018:8:14711.

38. Corrales-Garcia LL, Possani LD, Corzo G. Expression systems of human $\beta$ defensins: vectors, purification and biological activities. Amino Acids. 2011; 40:5-13.

39. De Schutter K, Lin Y C, Tiels P, Van Hecke A, Glinka S, Weber-Lehmann J, et al. Genome sequence of the recombinant protein production host pichia pastoris. Nat Biotechnol. 2009;27(6):561-66.

40. Damaso MCT, Almeida MS, Kurtenbach E, Martins OB, Pereira N, Andrade CMMC, et al. Optimized expression of a thermostable xylanase from Thermomyces lanuginosus in Pichia pastoris. Appl Environ Microbiol. 2003; 69:6064-607.

Ready to submit your research? Choose BMC and benefit from:

- fast, convenient online submission

- thorough peer review by experienced researchers in your field

- rapid publication on acceptance

- support for research data, including large and complex data types

- gold Open Access which fosters wider collaboration and increased citations

- maximum visibility for your research: over $100 \mathrm{M}$ website views per year

At BMC, research is always in progress.

Learn more biomedcentral.com/submissions 